\title{
EFFECT OF POLYBUTADIENE COMPOSITION ON THE GLASS TRANSITION TEMPERATURE OF SBS BLOCK COPOLYMERS
}

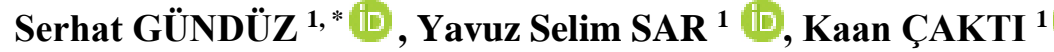 \\ ${ }^{1}$ Research and Development Center, Istanbul Teknik Insaat Sanayi ve Ticaret A.S., 34235, Istanbul, Turkey
}

\begin{abstract}
Gel permeation chromatography (GPC), nuclear magnetic resonance (NMR) spectroscopy, and elemental analysis techniques were used to study the molecular characteristics of six commercially available styrene-butadiene-styrene (SBS) block copolymers which are mostly used for modifying bitumen. The cis-1,4, trans-1,4, and 1,2-vinyl units in the polybutadiene (PB) parts and the styrene contents of the SBS block copolymers were investigated by means of ${ }^{1} \mathrm{H}-\mathrm{NMR}$ spectra. In addition, carbon and hydrogen contents were estimated using ${ }^{1} \mathrm{H}-\mathrm{NMR}$ measurements. These estimated values were confirmed using the results of elemental analysis (EA). The glass transition temperatures $\left(\mathrm{T}_{\mathrm{g}}\right.$ ) of SBS block copolymers were obtained using differential scanning calorimetry (DSC). The SBS block copolymers used in this study have different structural properties such as molecular weight and linearity. However, it is observed that the $\mathrm{T}_{\mathrm{g}}$-onset values are directly proportional to the percentage of the 1,2-vinyl units and inversely proportional to the percentage of the trans-1,4 units in the SBS block copolymers.
\end{abstract}

Keywords: SBS, Block copolymers; GPC, NMR,· Glass trantision temperature

\section{INTRODUCTION}

Block copolymer term is used to explain copolymers with long series or different monomers in the same continuous chain. The properties of block copolymers are related to the length of the sequence of repeating, or their domains. The domains in commercial block copolymers of styrene and butadiene are suitably long such that the products are flexible. SBS block copolymers are a type of thermoplastic elastomers which exhibit both the properties of plastic and rubber [1-4]. These properties provide SBS block copolymers a variety of application fields such as plastic modification, adhesives and especially bitumen modification [5-11]. Commercial SBS block copolymers are classified into two groups as linear and radial polymers. Radial SBS block copolymers are also called branched or star polymers $[4,12]$. Scheme 1 shows that SBS block polymers comprise polybutadiene mid-block and polystyrene (PS) end blocks. The polybutadiene part is responsible for the elasticity of the whole polymer. On the other hand, the polystyrene part increases the strength and rigidity of the polymer $[2,13]$.

Due to the structural benefits, SBS block polymers are widely used for modifying bitumen $[5,12,13]$. Bitumen is a residue of crude oil refining process. The properties of bitumen such as adhesivity, impermeability, and low cost make it most suitable binder in road paving. In addition, fatigue and aging properties of bitumen restrict its applications in industrial processes. SBS block copolymers enable swelling up to nine times its initial volume in maltene phase of bitumen and its continuous polymer phase helps to make polymer modified bitumen [7, 15-17]. SBS block copolymers improve the physical properties of bitumen to prevent rutting and cracking of asphalt in low or high temperature. Among polymers used for modified bitumens, SBS block copolymers provide higher performance such as penetration value, softening point and ductility value [18-20].

*Corresponding Author: serhatgunduz@istanbulteknik.com

Received: 19.10.2020 Published: 26.03.2021 
Commercially available SBS block copolymers for modification of bitumen contain approximately $30 \%$ styrene and 70\% butadiene. However, the SBS block copolymers exhibit different physical properties such as glass transition temperature [16]. Since the thermal sensitivity of bitumen causes cracking at low temperature, glass transition temperature is one of the most important parameter for bitumen used in asphalt pavement $[17,21]$. In this study, we report the structural characterization of six different commercial SBS block copolymers by means of GPC, ${ }^{1} \mathrm{H}-\mathrm{NMR},{ }^{13} \mathrm{C}-\mathrm{NMR}$, and elemental analysis techniques and the effects of molecular structure on $\mathrm{T}_{\mathrm{g}}$ values.

(c) (a)

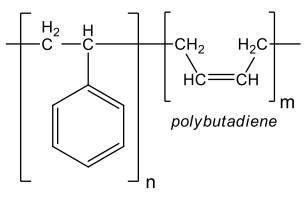

(b)

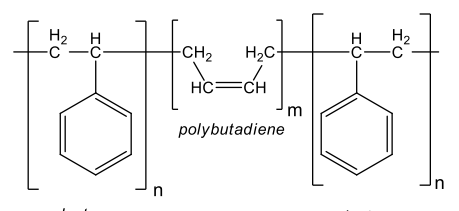

polystyrene polystyrene polystyrene

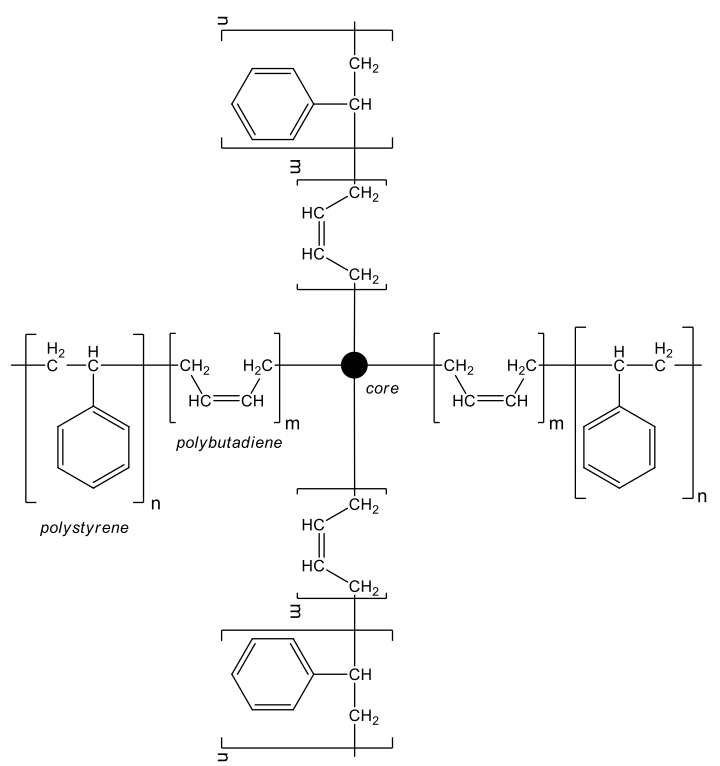

Scheme 1. The structures of SBS block copolymers: (a) Diblock; (b) Triblock; (c) Radial

\section{MATERIALS AND METHODS}

Six different commercially available SBS block copolymers were obtained from various sources and used without any further purification. Among the SBS block copolymers SBS-1 is a linear diblock copolymer. SBS-2, SBS-3, SBS-4, and SBS-5 correspond to linear triblock copolymers, and SBS-6 shows a radial copolymer.

\subsection{GPC measurements}

Molecular weight distributions of all SBS block copolymers were determined using an Agilent 1000 Series GPC system with a Refractive Index detector and PLgel $5 \mu \mathrm{m}$ MIXED-D column at a flow rate $0.5 \mathrm{~mL} / \mathrm{min}$., at $25{ }^{\circ} \mathrm{C}$. The samples were dissolved in THF and passed the solution through a 0.45 micrometer pore diameter teflon filter. THF butylated hydroxy toluene (BHT) was added as a flow marker. A calibration curve based on linear polystyrene standards was used to determine the molecular weights of SBS block copolymers.

\subsection{NMR Analysis}

${ }^{1} \mathrm{H}-\mathrm{NMR}$ and ${ }^{13} \mathrm{C}-\mathrm{NMR}$ spectroscopy measurements were performed on a Varian $600 \mathrm{MHz}$ spectrometer at room temperature $\left(23,5 \pm 5^{\circ} \mathrm{C}\right)$ in $\mathrm{CDCl}_{3}$. The solvent peaks appearing at $7.26 \mathrm{ppm}$ in ${ }^{1} \mathrm{H}$-NMR spectra and at $77.2 \mathrm{ppm}$ in ${ }^{13} \mathrm{C}-\mathrm{NMR}$ spectra were used as internal references. 


\subsection{Elemental Analysis}

Elemental analysis measurements were performed on a Thermo Finnigan Flash 1112 Series EA Model instrument.

\subsection{DSC Measurements}

DSC analyses were performed using a Perkin Elmer DSC8000. The experiments were carried out for all SBS block copolymers under nitrogen at a heating rate of $10^{\circ} \mathrm{C} / \mathrm{min}$.

\section{RESULTS AND DISCUSSION}

\subsection{GPC measurements}

The weight average molecular weights $(\mathrm{Mw})$, the number average molecular weights $(\mathrm{Mn})$ and the polydispersity index (PDI), Mw/Mn ratio, for all SBS block copolymers are shown in Table 1 . When PDI is equal to 1, polymer chains have identical molecular weight and length. Narrow distribution is more desirable for polymers. On the other word, if PDI is close to 1, the molecular properties of polymer chains are more identical in polymer domains [22]. Table 1 shows that SBS-1 has the lowest molecular weight and SBS-6 has the highest molecular weight among all SBS block copolymers. The molecular weight of radial SBS-6 is at least two times higher than the linear SBS block copolymers.

Table 1. GPC measurements of SBS block copolymers

\begin{tabular}{cccc}
\hline Sample & $M w$ & $M n$ & $M w / M n$ \\
\hline SBS-1 & 133.720 & 128.040 & 1.04 \\
SBS-2 & 228.420 & 208.220 & 1.10 \\
SBS-3 & 235.450 & 223.010 & 1.06 \\
SBS-4 & 235.590 & 226.100 & 1.04 \\
SBS-5 & 185.800 & 176.950 & 1.05 \\
SBS-6 & 490.380 & 455.690 & 1.08 \\
\hline
\end{tabular}

\section{2. ${ }^{13}$ C-NMR Analysis}

The ${ }^{13} \mathrm{C}$-NMR measurements were used to qualify the carbon atoms in the SBS block copolymers. As shown in Figure 1, the carbon atoms of aromatic rings for all SBS block copolymers were observed in the region 145 and 128-125 ppm. The alkenyl carbons of 1,2-vinyl-butadiene were observed at 144, 143, 115 and $114 \mathrm{ppm}$. The peaks appearing at 132-129 ppm shows the double bonds of cis-1,4-butadiene and trans-1,4-butadiene. The aliphatic carbon atoms appeared in the region 44-14 ppm [23, 24].

\section{3. ${ }^{1} \mathrm{H}-\mathrm{NMR}$ Analysis}

The ${ }^{1} \mathrm{H}$-NMR spectroscopy measurements were used to determine the percentage of polystyrene and polybutadiene in the SBS block copolymers. In addition, the compositions of 1,2-vinyl-butadiene, trans1,4-butadiene, and cis-1,4-butadiene in polybutadiene parts were quantified using the integrations of ${ }^{1} \mathrm{H}$ NMR spectra.

Figure 2 shows that the aromatic ring hydrogens for all SBS block copolymer samples were observed in the region 7.25-6.25 ppm. The alkenyl hydrogens of cis-1,4-butadiene and trans-1,4-butadiene appeared at around 5.43 and $5.38 \mathrm{ppm}$, respectively. The peaks appearing at around 5.55 and $4.98 \mathrm{ppm}$ confirmed that the presence of alkenyl hydrogens in 1,2-vinyl-butadiene structure. The aliphatic hydrogens in SBS block copolymer chains appeared in the region 2.20-0.80 ppm [23-25]. 
Gündüz et al. / Eskişehir Technical Univ. J. of Sci. and Tech. A - Appl. Sci. and Eng. 22 (1) - 2021
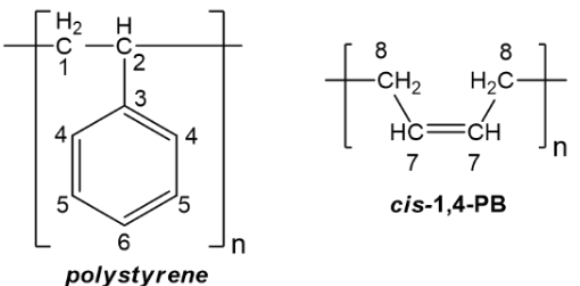

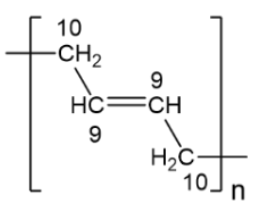

trans-1,4-PB

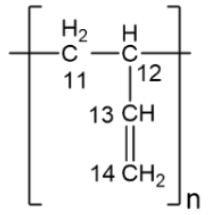

1,2-vinyl-PB

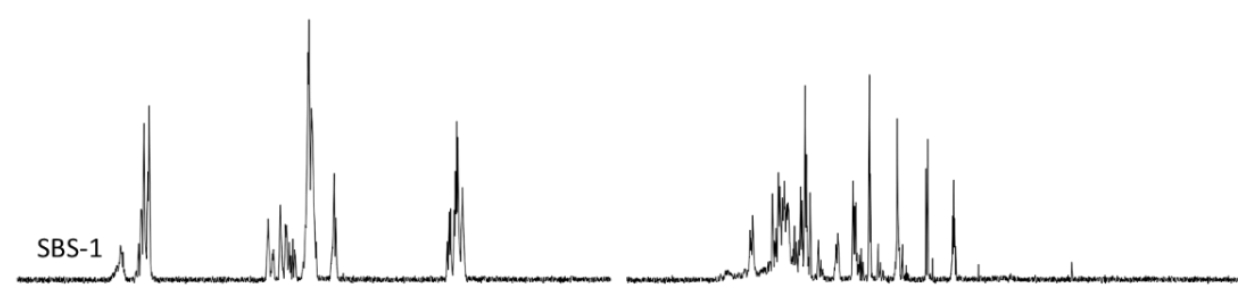

SBS-2

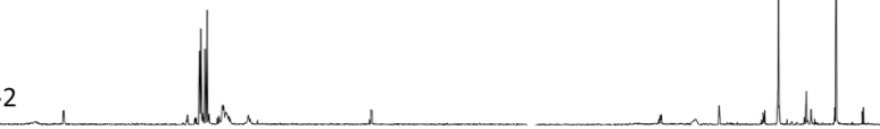

SBS-3

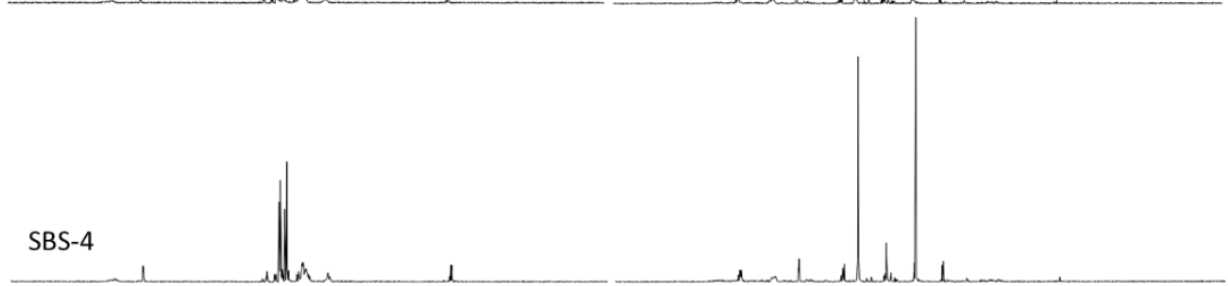

SBS-5

Ni
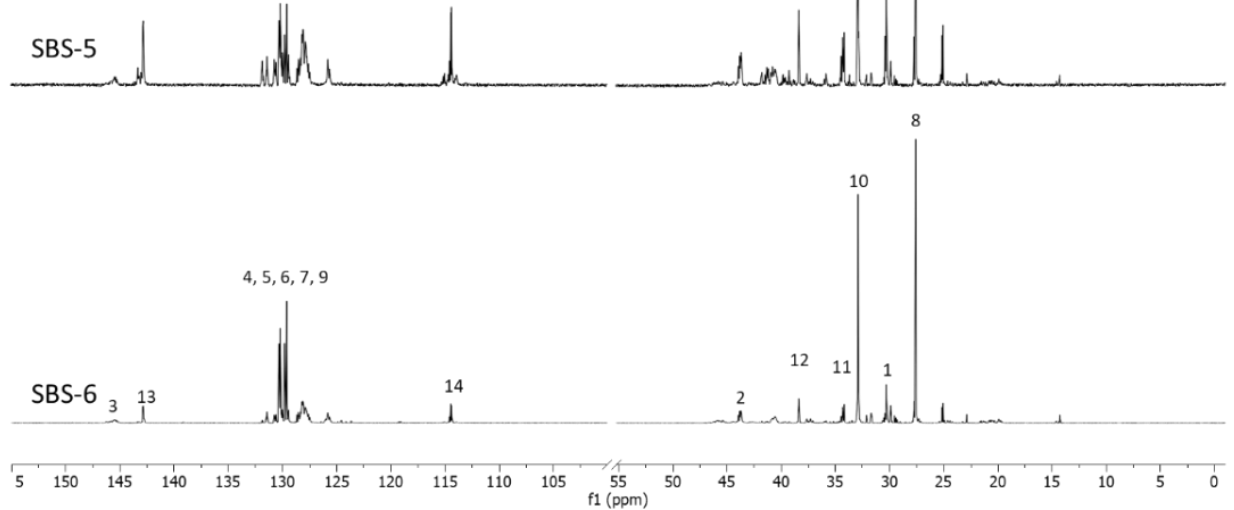

Figure 1. ${ }^{13} \mathrm{C}-\mathrm{NMR}$ spectra of the SBS block copolymers 
Gündüz et al. / Eskişehir Technical Univ. J. of Sci. and Tech. A-Appl. Sci. and Eng. 22 (1)-2021
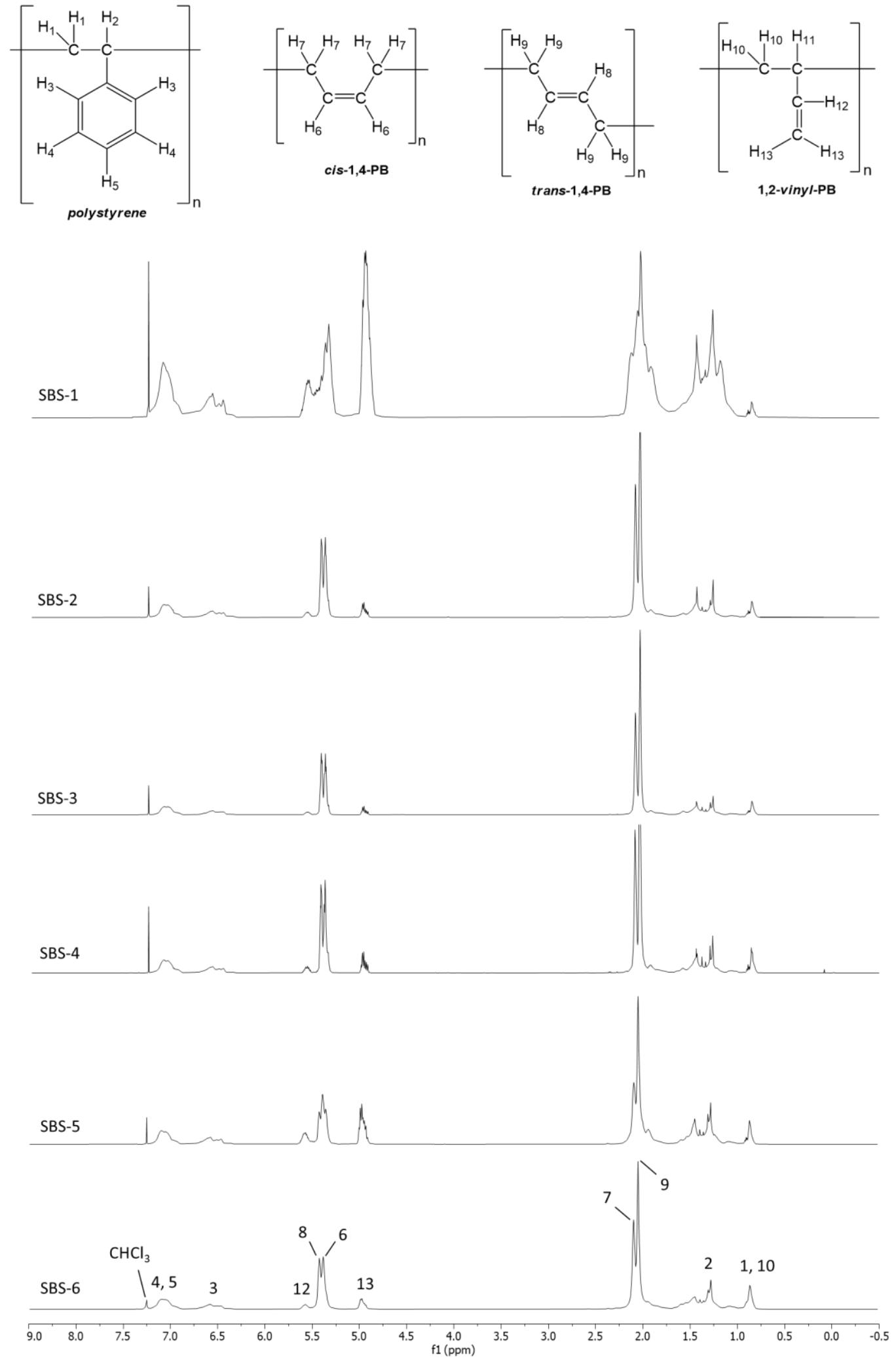

Figure 2. ${ }^{1} \mathrm{H}-\mathrm{NMR}$ spectra of the SBS block copolymers 
Figure 3 is an example to show the integration of the ${ }^{1} \mathrm{H}-\mathrm{NMR}$ spectrum of SBS-2 for the rest of SBS block copolymers. The contents of styrene and butadiene were analysed according to the integration values. In addition, the compositions of 1,2-vinyl, trans-1,4 and cis-1,4 butadiene conformations in SBS block copolymers were estimated using the ${ }^{1} \mathrm{H}-\mathrm{NMR}$ spectra and the results are shown in Table 2 . In order to analyse the styrene contents in SBS block copolymers and the compositions of polybutadiene parts, the following equations (1-8) were used [24, 25]. The estimated styrene and butadiene contents are given in Table 3 .<smiles>CCCc1c(C)c(C)c(C)c(C(C)(C)C)c1C</smiles><smiles>CC=C(C)C1(C)CCC1C</smiles>

cis-1,4-PB
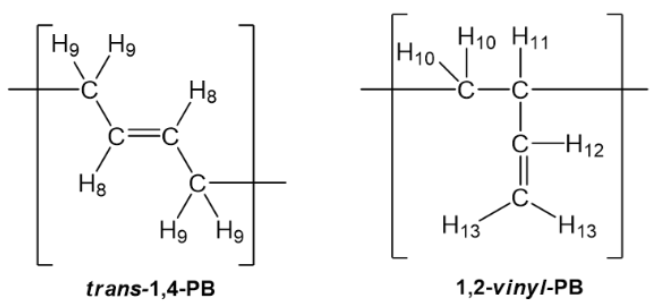
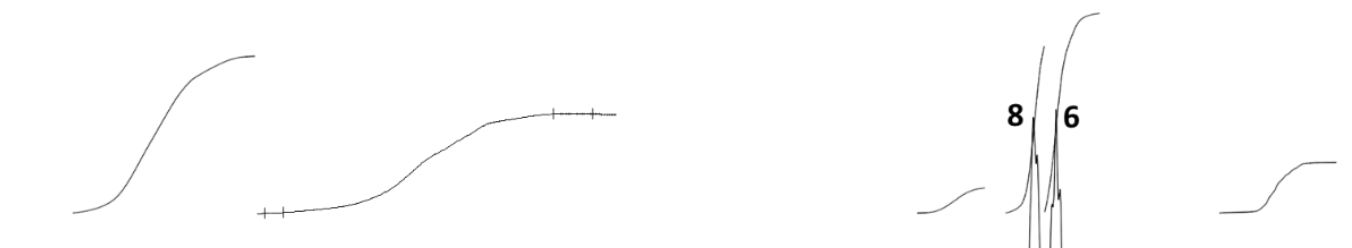

$\mathrm{CHCl}_{3}$<smiles>CCC</smiles>

4,5

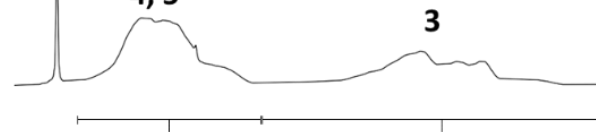

12
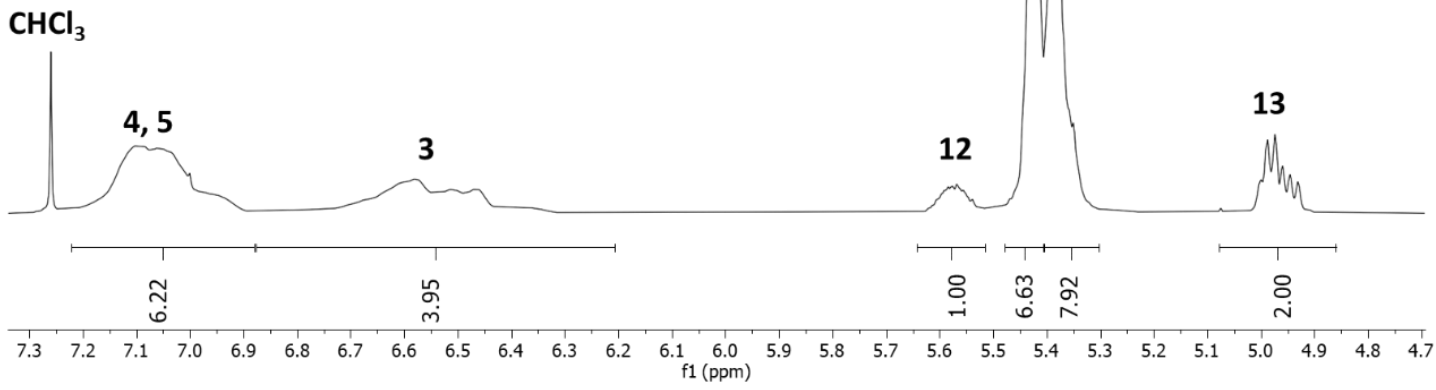

Figure 3. ${ }^{1} \mathrm{H}-\mathrm{NMR}$ integration for SBS-2

$\mathrm{N}_{1}=$ mole ratio of cis-1,4-butadiene for polybutadiene part, $\mathrm{N}_{2}=$ mole ratio of trans-1,4-butadiene for polybutadiene part, $\mathrm{N}_{3}=$ mole ratio of 1,2-vinyl-butadiene for polybutadiene part, $\mathrm{N}_{4}=$ mole ratio of styrene for SBS block copolymer, $\mathrm{N}_{5}=$ mole ratio of butadiene for SBS block copolymer, $\mathrm{H}_{6}=$ ratio of ${ }^{1} \mathrm{H}-\mathrm{NMR}$ integral for $\mathrm{cis}$-1,4-butadiene unit, $\mathrm{H}_{8}=$ ratio of ${ }^{1} \mathrm{H}$-NMR integral for trans-1,4-butadiene unit, $\mathrm{H}_{12}$ and $\mathrm{H}_{13}=$ ratios of ${ }^{1} \mathrm{H}-\mathrm{NMR}$ integral for 1,2-vinyl butadiene unit, $\mathrm{H}_{3}, \mathrm{H}_{4}$, and $\mathrm{H}_{5}=$ ratios of ${ }^{1} \mathrm{H}-\mathrm{NMR}$ 
integral for aromatic unit, $\mathrm{Mw}_{\mathrm{S}}=$ Molecular weight of styrene, $\mathrm{Mw}_{\mathrm{B}}=$ Molecular weight of butadiene, $\mathrm{Mw}_{\mathrm{SBS}}=$ Molecular weight of SBS block copolymer, S\%= Styrene content of SBS block copolymer by weight. B\%= Butadiene content of SBS block copolymer by weight.

Table 2. Compositions of butadiene units in polybutadiene parts

\begin{tabular}{cccc}
\hline Sample & $\begin{array}{c}\text { cis-1,4 } \\
(\%)\end{array}$ & $\begin{array}{c}\text { trans-1,4 } \\
(\%)\end{array}$ & $\begin{array}{c}\text { 1,2-vinyl } \\
(\%)\end{array}$ \\
\hline SBS-1 & 23 & 10 & 67 \\
SBS-2 & 48 & 40 & 12 \\
SBS-3 & 47 & 44 & 9 \\
SBS-4 & 48 & 39 & 13 \\
SBS-5 & 35 & 29 & 36 \\
SBS-6 & 49 & 37 & 14 \\
\hline
\end{tabular}

Table 3. Styrene-butadiene contents of the SBS block copolymers

\begin{tabular}{ccc}
\hline Sample & Styrene content $(\%)$ & $\begin{array}{c}\text { Butadiene content } \\
(\%)\end{array}$ \\
\hline SBS-1 & 34 & 66 \\
SBS-2 & 32 & 68 \\
SBS-3 & 31 & 69 \\
SBS-4 & 31 & 69 \\
SBS-5 & 31 & 69 \\
SBS-6 & 31 & 69 \\
\hline
\end{tabular}

\subsection{Elemental Analysis}

The elemental analysis results show that all SBS block copolymers have approximately $10 \%$ hydrogen content and $90 \%$ carbon by weight. The hydrogen content was also estimated using ${ }^{1} \mathrm{H}-\mathrm{NMR}$ spectra. The mole percentage of carbon atoms and the molar ratio $\mathrm{H} / \mathrm{C}$ were also calculated using ${ }^{1} \mathrm{H}-\mathrm{NMR}$ spectra according to the following equations (12-16). The comparison between elemental analysis and ${ }^{1} \mathrm{H}-\mathrm{NMR}$ measurements are listed in Table 4. As it is seen in the table, the values obtained from elemental analysis and ${ }^{1} \mathrm{H}-\mathrm{NMR}$ spectroscopy are very close to each other.

$$
\begin{aligned}
& C \%=\frac{M w_{C} \times\left(N_{4} \times \# C_{S}+N_{5} \times \# C_{B}\right)}{M w_{C} \times\left(N_{4} \times \# C_{S}+N_{5} \times \# C_{B}\right)+M w_{H} \times\left(N_{4} \times \# H_{S}+N_{5} \times \# H_{B}\right)} \times 100 \\
& m o l ~ C \%=\frac{C \%}{M w_{C}} \quad(14), \quad m o l ~ H \%=\frac{H \%}{M w_{H}} \quad(15), \quad H / C=\frac{m o l ~ H \%}{m o l ~ C \%}
\end{aligned}
$$$$
H \%=100-C \%
$$

$\# C_{S}=$ number of carbon atoms per styrene unit for one molecule of SBS block copolymer, $\# C_{B}=$ number of carbon atoms per butadiene unit for one molecule of SBS block copolymer, $\# \mathrm{H}_{\mathrm{S}}=$ number of hydrogen atoms per styrene unit for one molecule of SBS block copolymer, $\mathrm{AH}_{\mathrm{B}}=$ number of hydrogen atoms per butadiene unit for one molecule of SBS block copolymer, $\mathrm{Mw}_{\mathrm{C}}=$ atomic weight of carbon, $\mathrm{Mw}_{\mathrm{H}}=$ atomic weight of hydrogen, $\mathrm{C} \%=$ percentage of carbon by weight, $\mathrm{H} \%=$ percentage of hydrogen by weight, $\mathrm{mol} \mathrm{C} \%=$ mole percentage of carbon, $\mathrm{mol} \mathrm{H} \%=$ mole percentage of hydrogen, $\mathrm{H} / \mathrm{C}=$ molar ratio of hydrogen. 
Gündüz et al. / Eskişehir Technical Univ. J. of Sci. and Tech. A - Appl. Sci. and Eng. 22 (1) - 2021

Table 4. Elemental contents of the SBS block copolymers

\begin{tabular}{ccccccccc}
\hline Sample & $\begin{array}{c}C \% \\
(E A)\end{array}$ & $\begin{array}{c}C \% \\
\left({ }^{1} H-N M R\right)\end{array}$ & $\begin{array}{c}H \% \\
(E A)\end{array}$ & $\begin{array}{c}H \% \\
\left({ }^{l} H-N M R\right)\end{array}$ & $\begin{array}{c}\text { Mol C\% } \\
(E A)\end{array}$ & $\begin{array}{c}\text { Mol C } \% \\
\left({ }^{l} H-N M R\right)\end{array}$ & $\begin{array}{c}H / C \text { ratio } \\
(E A)\end{array}$ & $\begin{array}{c}H / C \text { ratio } \\
\left({ }^{l} H-N M R\right)\end{array}$ \\
\hline SBS-1 & 90.0 & 89.7 & 10.0 & 10.3 & 7.50 & 7.48 & 1.34 & 1.38 \\
SBS-2 & 90.0 & 89.9 & 10.0 & 10.1 & 7.50 & 7.49 & 1.34 & 1.35 \\
SBS-3 & 90.0 & 89.9 & 10.0 & 10.1 & 7.42 & 7.49 & 1.35 & 1.35 \\
SBS-4 & 90.0 & 89.9 & 10.0 & 10.1 & 7.50 & 7.49 & 1.34 & 1.35 \\
SBS-5 & 90.0 & 89.7 & 10.0 & 10.3 & 7.42 & 7.48 & 1.35 & 1.35 \\
SBS-6 & 90.0 & 89.7 & 10.0 & 10.3 & 7.25 & 7.48 & 1.38 & 1.34 \\
\hline
\end{tabular}

\subsection{DSC Analysis}

SBS-1 and SBS-5 have higher vinyl content than the other linear and radial SBS block copolymers and therefore they have higher $T_{\mathrm{g}}$-onset values among six SBS block copolymers. The lowest $\mathrm{T}_{\mathrm{g}}$-onset value of PB was observed for SBS-3. Table 5 shows SBS-1 has the highest $\mathrm{T}_{\mathrm{g}}$-onset value for PB.

Olson et al. investigated a composition dependency of high vinyl polybutadiene (HVBD)/cispolyisoprene (CPI) blends [26]. This study showed that $\mathrm{T}_{\mathrm{g}}$ values are directly proportional to the percentage of the 1,2-vinyl-butadiene units for PB obtained from ${ }^{1} \mathrm{H}-\mathrm{NMR}$ measurements. In our investigation, the $\mathrm{T}_{\mathrm{g}}$-onset values for each SBS block copolymer were plotted against the percentage of the 1,2-vinyl-butadiene units (Figure 5). Although all six SBS block copolymers have different structural properties such as molecular weight and linearity, the $\mathrm{T}_{\mathrm{g}}$-onset values are directly proportional to the percentage of the 1,2-vinyl-butadiene units. In addition, as it is seen in Figure 5, the results showed that the $\mathrm{T}_{\mathrm{g}}$-onset values are inversely proportional to the percentage of the trans-1,4-butadiene units.

Table 5. Glass transition temperatures

\begin{tabular}{cc}
\hline Sample & Onset of $T_{g} P B$ \\
\hline SBS-1 & -42.6 \\
SBS-2 & -90.2 \\
SBS-3 & -91.8 \\
SBS-4 & -88.9 \\
SBS-5 & -69.2 \\
SBS-6 & -87.1 \\
\hline
\end{tabular}

(a)

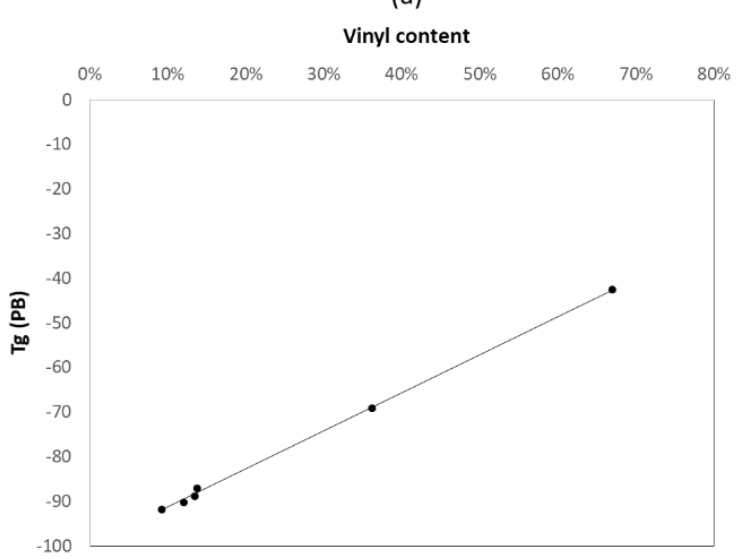

(b)

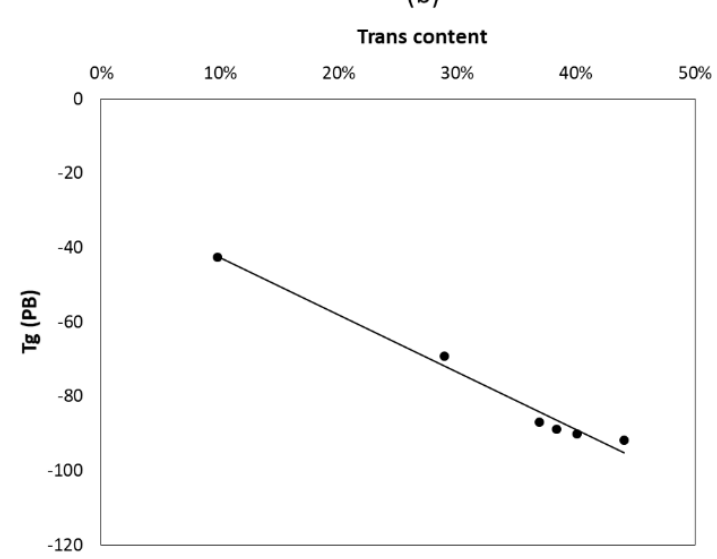

Figure 5. Linear relationship for SBS: (a) $\mathrm{T}_{\mathrm{g}}$-onset and 1,2-vinyl-butadiene content; (b) $\mathrm{T}_{\mathrm{g}}$-onset and trans-1,4butadine content 


\section{CONCLUSIONS}

Six commercial SBS block copolymers were characterized using NMR spectroscopy and elemental analysis. The compositions of 1,2-vinyl, trans-1,4, and cis-1,4 units in polybutadiene part of these copolymers were determined using ${ }^{1} \mathrm{H}-\mathrm{NMR}$ spectroscopy. The results of the elemental analysis were compared to the ${ }^{1} \mathrm{H}$-NMR measurements. The values obtained from elemental analysis and the ${ }^{1} \mathrm{H}-\mathrm{NMR}$ spectroscopy are very close to each other, hence the elemental analysis results confirmed the accuracy of the calculations on ${ }^{1} \mathrm{H}-\mathrm{NMR}$ integration.

DSC results showed that the $\mathrm{T}_{\mathrm{g}}$-onset values are directly proportional to the percentage of the 1,2-vinyl units and inversely proportional to the percentage of the trans-1,4 units in the SBS block copolymers which have different structural properties. Since the thermal sensitivity of bitumen causes cracking at low temperature, bitumen can be modified using SBS block copolymers which have low $\mathrm{T}_{\mathrm{g}}$-onset of polybutadiene. Among six SBS block copolymers, SBS-3 has the lowest 1,2-vinyl and the highest trans1,4 butadiene units, thus SBS-3 has the lowest $\mathrm{T}_{\mathrm{g}}$-onset value of polybutadiene. The results of this analytical study recommend to use low 1,2-vinyl and high trans-1,4 content SBS molecules in bitumen modification as they have relatively low glass transition temperatures.

\section{ACKNOWLEDGEMENTS}

The financial support of İstanbul Teknik Insaat Sanayi ve Ticaret A.S. is gratefully acknowledged.

\section{CONFLICT OF INTEREST}

The author stated that there are no conflicts of interest regarding the publication of this article.

\section{REFERENCES}

[1] Visakh PM, Thomas S, Chandra AK, Mathew AP. Advances in elastomers i: Blends and interpenetrating networks. Berlin, Heidelberg, Germany: Springer Verlag, 2013.

[2] Shanks R, Kong I. Thermoplastic elastomers. Rijeka, Croatia: InTech, 2012, 137-154.

[3] Mark JE. Polymer Data Handbook. 1st ed. Oxford, UK: Oxford University Press Inc., 1999.

[4] Drobny DJ. Handbook of thermoplastic elastomers. Norwich, NY, USA: William Andrew Inc., 2007.

[5] Airey GD. Styrene butadiene styrene polymer modification of road bitumens. Journal of Materials Science 2004; 39(3): 951-959.

[6] Isacsson U, Lu X. Characterization of bitumens modified with SEBS, EVA and EBA polymers. Journal of Materials Science 1999; 34: 3737 - 3745.

[7] Feng H, Lu X, Wang W, Kang NG, Mays JW. Block copolymers: synthesis, self-assembly, and applications. Polymers 2017; 9: 494.

[8] Zhu J, Birgisson B, Kringos N. Polymer modification of bitumen: Advances and challenges. European Polymer Journal 2014; 54: 18-38.

[9] Kumar P, Khan MT, Singh M. Evaluation of physical properties of sbs modified bitumen and effect of aging. Elixir Chemical Engineering 2012; 46: 8299-8303. 
[10] Porto M, Caputo P, Loise V, Eskandarsefat S, Teltayev B and Rossi CO. Bitumen and bitumen modification: a review on latest advances applied sciences 2019; 9: 742.

[11] Speight JG. The Chemistry and Technology of Petroleum. NY, USA: Marcel Dekker Inc., 1999.

[12] Schaur A, Unterberger S, Lackner R. Impact of molecular structure of sbs on thermomechanical properties of polymer modified bitumen. European Polymer Journal 2017; 96: 256-265.

[13] Lynwood C. Polystyrene synthesis, characteristics and applications. NY, USA: Nova science publisher Inc., 2014.

[14] Simnofske D, Mollenhauer K. Precision of iatroscan method for assessment of SARA compounds in bitumen. RILEM 252-CMB-Symposium on Chemo Mechanical Characterization of Bituminous Materials 17-18 September 2018; 162-167.

[15] Liang M, Ren S, Fan W, Xin X. Storage stability and its relationship with microstructure of SBS modified de-oiled asphalt. Proceedings of the 2016 4th International Conference on Mechanical Materials and Manufacturing Engineering 15-16 October 2016; 585-588.

[16] Munteanua SB, Vasile C. Spectral and thermal characterization of styrene butadiene copolymers with different architectures. Polymer Journal 2005; 33: 209-213.

[17] Hunter RN, Self A, Read J. Shell Bitumen Handbook. 6th ed. London, UK: ICE Publishing, 2015.

[18] Sengoz B, Isikyakar G. Evaluation of the properties and microstructure of SBS and EVA polymer modified bitumen. Construction and building materials 2008; 22: 1897-1905.

[19] Zhang C, Wang H, You Z, Gao J and Irfan M. Performance test on styrene-butadiene-styrene (SBS) modified asphalt based on the different evaluation methods. Applied Sciences 2019; 4: 467.

[20] Kumar UA, Satyanarayana PVV. Comparison of the polyethylene and SBS polymer modified bitumen's effect - a case study. International Journal of Engineering Trends and Technology 2015; 22(7): 325-330.

[21] Kriz P, Stastna J, Zanzotto L. Glass Transition and Phase Stability in Asphalt Binders. Road Materials and Pavement Design. 2008; 9: 37-65.

[22] Strsup-Gwdiiner M, Newcomb DE. Polymer Literature Review. Minnesota, USA: Minnesota department of transportation office of research administration, 1995.

[23] Sardelis K, Michels HJ, Allen G. Graded block and randomized copolymers of butadiene-styrene. Polymer 1984; 25: 1011-1019.

[24] Ban HT, Kase T, Kawabe M, Miyazawa A, Ishihara T, Hagihara H, Tsunogae Y, Murata M, and Shiono T. A new approach to styrenic thermoplastic elastomers: synthesis and characterization of crystalline styrene-butadiene-styrene triblock copolymers. Macromolecules 2006; 39: 171-176.

[25] Zhang Z, Zhang L, Li Y, Xu H. Styrene-butadiene-styrene/montmorillonite nanocomposites synthesized by anionic polymerization. Journal of Applied Polymer Science 2005; 99: 2273-2278.

[26] Olson BG, Srithawatpongz R, Pengyk ZL, McGerveyy JD, Ishidaz H, Maierx TM, Halasa AF. Composition dependence $\mathrm{T}_{\mathrm{g}}$ of in high-vinyl polybutadiene/ cis-polyisoprene blends studied by means of positron annihilation lifetime spectroscopy. Journal of Physics: Condensed Matter 1998; 10: $10451-10459$. 